\title{
Preparation of Liposomes from Halophilic Bacteria and Their Evaluation for Drug Delivery
}

\author{
Parastoo Arzani ${ }^{1}$ and Majid Baserisalehi ${ }^{2 *}$ \\ ${ }^{1}$ Ph.D. student of Cellular and Molecular Biology, Department of Microbiology, Kazeroon Branch, Islamic Azad University, Iran \\ ${ }^{2}$ Associate Professor, Department of Microbiology, Kazeroon Branch, Islamic Azad University, Iran
}

*Corresponding author: Majid Baserisalehi, Associate Professor, Department of Microbiology, Kazeroon Branch, Islamic

Azad University, Kazeroun, Iran

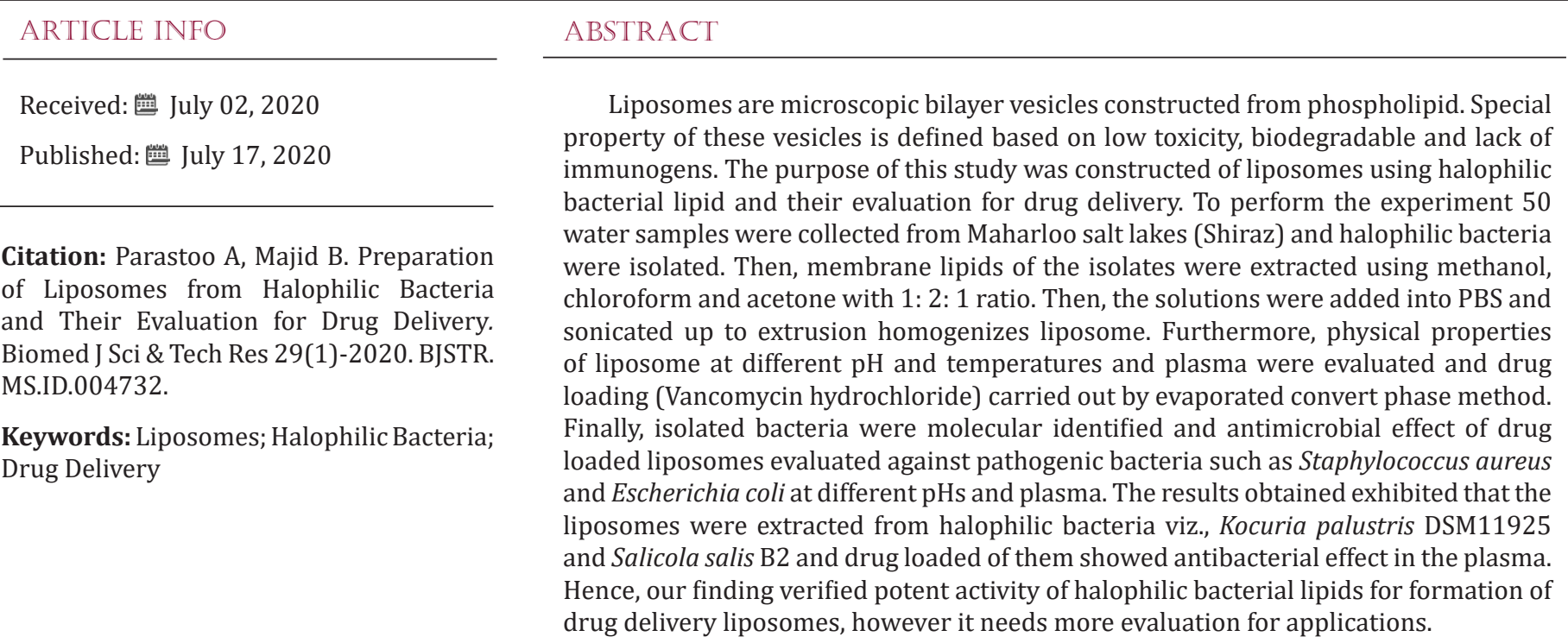

\section{Introduction}

Liposome is two-layer microscopic vesicle made of phospholipid, which have a hydrophilic and a hydrophobic head. Liposomes, due to amphipathic properties, provide drug delivery for hydrophilic and lipophilic drugs. Characteristics such as low intrinsic toxicity, biodegradability and lack of immunogenicity have led to the development of liposomes as a drug delivery system. Liposomes are like capsule-shaped microstructures that are made of sterol phospholipids. The structure of the liposome is one that allows the carrying drugs to various parts of the body [1]. The method of drug loading by liposomes is that drugs and hydrophobic materials are placed between the liposome lipid membranes. However, there is also the possibility of absorption on the surface of liposomes for drugs and hydrophilic materials. When liposomes are used to deliver drugs, they protect healthy cells against the toxicity of drugs and prevent the concentration of drugs in vulnerable tissues, such as the liver and kidneys [2]. Therefore, liposomes are especially effective in the treatment of diseases. Nowadays, liposomes considered as drug delivery to HIV-infected people. These liposomes carry anti-HIV drugs, such as siRNA, to human T-cells. Mechanism of liposomes action is stranger invader by the endothelial system of the blood and phagocyte by T cells and the loaded drug are released into these phagocyte cells [3]. Another application of liposomes is activation of the immune response in vaccinated mice with protein antigen of respiratory syncytial virus loaded in liposomes prepared from deinococcus radiodurans [4]. Several studies verified that stability of ribosomes depended on their charge and these charge could be changes at different pHs. In addition, liposomes are bilayer lipid and physical character of lipid can be changed at different temperatures. Therefore, $\mathrm{pH}$ and temperature can significantly affect the stability of liposomes. On the other hand, property of bacterial membrane allows them to 
survive at different environments [5]. Therefore, characteristic of bacterial membrane can be changed based on the environments and clearly it led to change liposome characteristics [6]. In the current study, we aim to extract halophilic bacteria from maharoo Lake in Shiraz, Iran and to prepare drug loading liposomes with high encapsulation efficiency.

\section{Material and Methods}

\section{Sampling and Isolation of Halophilic Bacteria}

A total of 50 water samples were collected from Maharloo Lake, in shiraz, Iran. The samples were transferred to the laboratory within 2 hours and subjected to microbiological analysis. To perform the experiment, $10 \mathrm{ml}$ of each sample was centrifuged for 15 minutes at $3000 \mathrm{rpm}$. Then, sediment in the tube added into the nutrient broth with different salt concentrations $(2,4,6$, 8,10 and $12 \%$ ) and the tubes were kept in incubator at 30C. After 24- 48 hours a loop of each suspension was streaked on trypticase soy agar containing $10 \% \mathrm{NaCl}$ and kept in incubator at $30 \mathrm{C}$ for 24 48 hours. The isolated colonies were picked up and subjected to phenotypical identification using Gram stain and biochemical tests viz., catalase, oxidase and sugars [7].

\section{Growth Optimization of Halophilic Bacteria Isolates at Different Temperatures and pHs}

The effect of different temperatures on growth of isolates was carried out using nutrient broth medium with 6\% salt concentration. Then, the isolates were inoculated, and the broth cultures were kept at different temperatures $(20,25,30,35,40$ and 45 ) for 48 hours. The bacterial growth rate of each tube was measured by spectrophotometer at $620 \mathrm{~nm}$. Nutrient broth medium was prepared with optimum salt and yeast extracts concentrations adjusted at different $\mathrm{pH}$ of $6,7,8,9$ and 10. Then each isolate inoculated into the broth medium and kept at 30 for 48 hours. Then the bacterial growth rate of each tube was measured by spectrophotometer at $620 \mathrm{~nm} \mathrm{[7].}$

\section{Extraction of Lipids from Halophilic Bacterial Isolates and Preparation of Proliposomes}

To perform the experiment, $1 \mathrm{ml}$ solution of methanol, chloroform and acetone with 1: 2: 1 ratio was added to $1.5 \times 10^{8}$ bacterial cells ( 0.5 McFarland standard tubes) in the sterile tubes and the tubes were closed for $48 \mathrm{~h}$. Subsequently, the surface phase of each tube withdrew and after evaporation of organic solvents in the oven extracted bacterial lipid added into sterile distilled water. After adding PBS, the lipid film completely hydrated, and the lipid gets swelled and was ready for formation of liposome. Sonication of lipid in the present study was carried out to extrusion homogenizes liposome [8].

\section{Evaluation of Liposome Stability at Different pHs and Temperatures and in Plasma}

To determine stability of liposomes at different pHs and temperatures, $\mathrm{pH}$ value solutions were prepared ( 3 to 10) using hydrochloric acid and sodium hydroxide. Then, $0.1 \mathrm{ml}$ liposomes solution was added to each of the tube and the morphological property of the liposomes was assessed at different time of 30, 60, 90 and 120 minutes by an optical microscope. To determine stability of liposomes at different temperatures, $0.1 \mathrm{ml}$ liposome solution was kept at temperatures of $10,20,30$ and $37^{\circ} \mathrm{C}$ for two hours. Then, the morphological property of the liposomes was evaluated at different time of 30, 60, 90 and 120 minutes by an optical microscope [9]. Subsequently, to determine liposome stability in blood plasma, $2 \mathrm{ml}$ of blood plasma was added to the sterile tubes. Then, $0.1 \mathrm{ml}$ liposome solution was added to the tube and morphological property of the liposomes were examined at different time of 30,60, 90 and 120 minutes, using optical microscope [10].

\section{Drug Loading}

Drug liposome loading was carried out using reverse phase evaporation method. To perform the experiment $125 \mathrm{mg}$ of vancomycin hydrochloride was added to $6 \mathrm{ml}$ of distilled water. Then, hydrated lipid extracted from halophilic bacterial was mixed with vancomycin hydrochloride solution and sonicated completely up to formation of Vancomycin hydrochloride-loaded liposome (VANH-Lips). Then, VANH-Lips were washed three times by sterile distilled water [11]. In the present study, the effect of vancomycin loaded liposomes on Staphylococcus aureus (ATCC 25923) was evaluated. To perform the experiment two tubes containing $0.9 \mathrm{ml}$ sterile distilled water and $0.9 \mathrm{ml}$ plasma were separately prepared and $0.1 \mathrm{ml}$ fresh culture of Staphylococcus aureus (0.5 Mcfarland tube) was added into each tube. Then, $0.1 \mathrm{ml}$ of VANH-Lips was added into each tube and kept for $12 \mathrm{~h}$ at $20{ }^{\circ} \mathrm{C}$. Then, $0.1 \mathrm{ml}$ of the solutions streaked on blood agar medium and the plated kept in incubator at $37^{\circ} \mathrm{C}$. After $24 \mathrm{~h}$ growth of Staphylococcus aureus was evaluated and considered as verification of vancomycin loaded in the liposomes.

\section{Molecular Identification of Halophilic Isolates}

For final confirmation, it was used 16S rRNA with $27 \mathrm{~F}$ and $1492 \mathrm{R}$ primers. Specifications of primers such as primer sequencing, thermal profile and target genes are shown in Table 1. DNA extraction was performed using the DNG kit obtained from Sinagene Co for molecular identification of the isolates and PCR was performed using the above-mentioned temperatures. To ensure the amplification of the 16S rRNA gene, the isolates were electrophoresed and sent to the South Korean Macro Corporation for sequencing the 16S rRNA genes. 
Table 1: Universal primers used for identification of halophilic bacteria isolates.

\begin{tabular}{|c|c|c|}
\hline Primer & $\begin{array}{c}\text { Target } \\
\text { gene }\end{array}$ & Temperature Pattern \\
\hline 27F 5- & & $94{ }^{\circ} \mathrm{C}-3$ min \\
AGAGTTTGATCMTGGCTCAG-3 & 16S rRNA & $94{ }^{\circ} \mathrm{C}-1$ min \\
1492R & $57-58{ }^{\circ} \mathrm{C}-1$ min-30 cycles \\
5-GGTTACCTTGTTACGACTT-3 & & $72{ }^{\circ} \mathrm{C}-90 \mathrm{sec}$ \\
& & $72^{\circ} \mathrm{C}-10 \mathrm{~min}$ \\
\hline
\end{tabular}

\section{Result}

\section{Isolation of Halophilic Bacteria}

Although, many halophilic bacterial strains were isolated from 50 samples, two strains were selected for extraction of their lipids. This selection was done based on their size, fast growing and salt tolerance $(10 \% \leq \mathrm{NaCl})$. One of which (Mh1) was Gram-positive cocci arranged in pairs, short chains, tetrad and non-motile and second strain (Mh2) was Gram-negative, rod-shaped and motile.

\section{Growth Optimization of Halophilic Bacteria Isolates}

Both strains were grown in high concentration of salt (more than $10 \% \mathrm{NaCl}$ ). Optimum temperature for them was $35^{\circ} \mathrm{C}$ and optimum pH for Mh1 was 9 and for Mh2 was 8.

\section{Stability of Proliposome at Different pHs And Temperatures and in Plasma}

The result indicative that proliposomes had spherical vesicles with particle sizes ranging from $10 \mu \mathrm{m}$ to several nanometers. Larger sizes were observed in acidic $\mathrm{pH}$ and smaller in alkaline $\mathrm{pH}$. However, in neutral $\mathrm{pH}$ the size of liposomes was intermediated. In addition, liposome size was increased at $35^{\circ} \mathrm{C}$ and decreased at $4^{\circ} \mathrm{C}$. By exposing the liposomes to plasma, their size increased and eventually disappeared after $2 \mathrm{~h}$ (Figures $1 \& 2$ ).

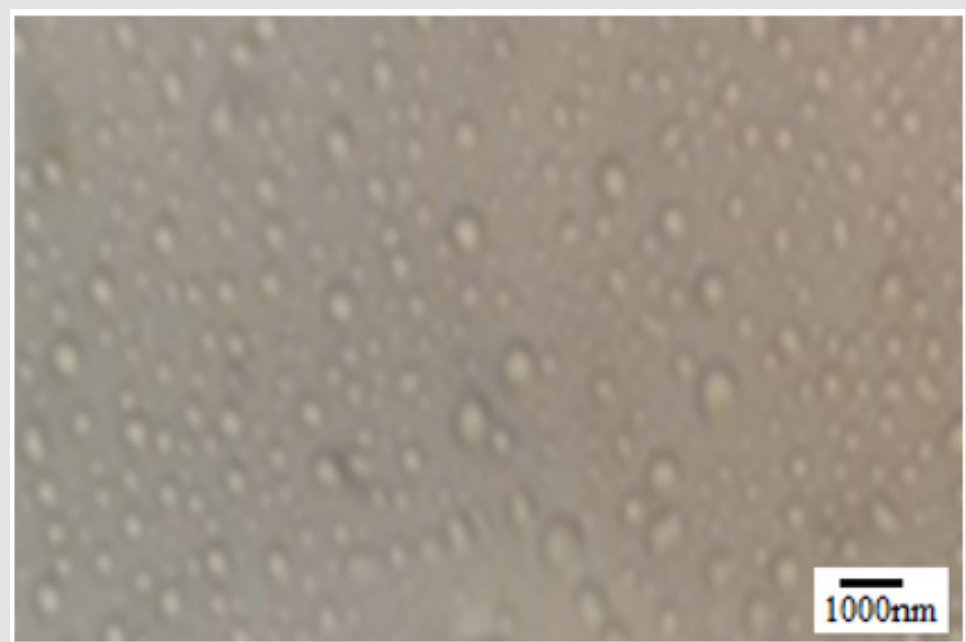

Figure 1: Preparation of proliposomes from halophilic bacterium lipid.

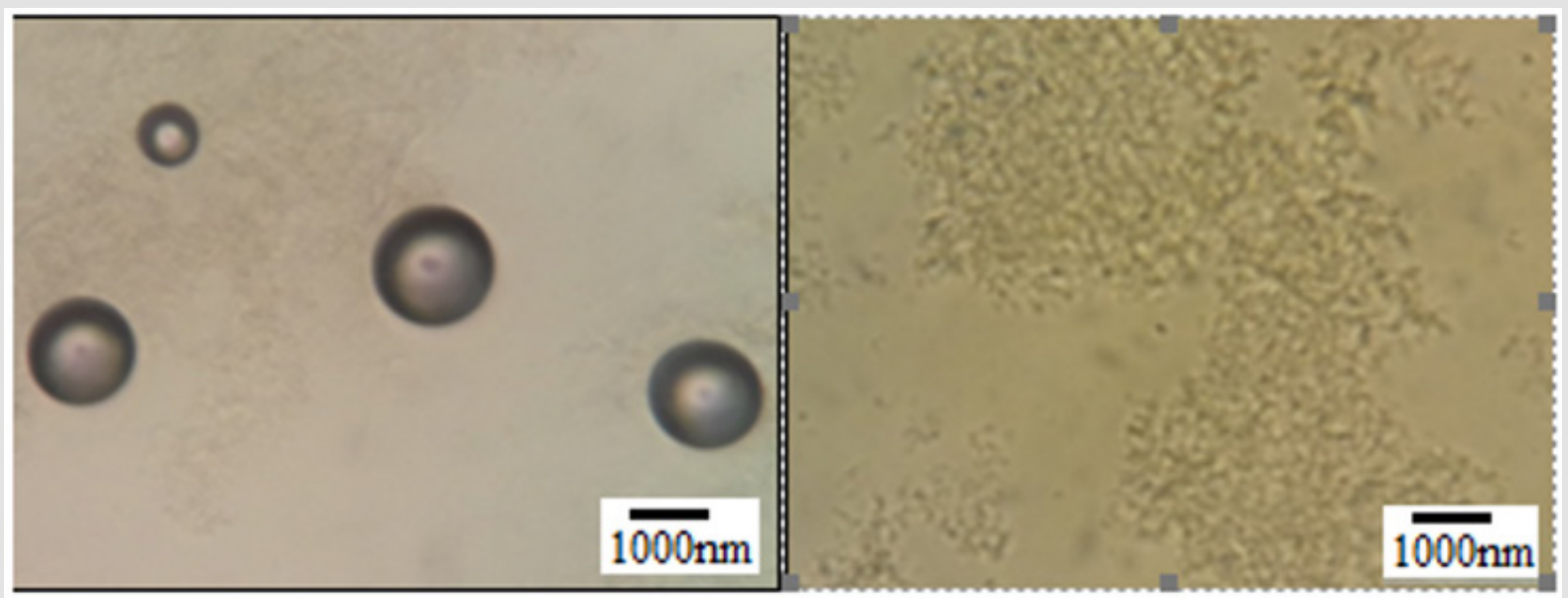

Figure 2: liposomes in blood plasma (optical microscope and magnification (100X): Left to right: The size of liposome in plasma increased and disappeared after $2 \mathrm{~h}$. 
Antimicrobial Effect of Vancomycin HydrochlorideLoaded Liposome (VANH-Lips) On Staphylococcus Aureus

The results obtained indicated that Staphylococcus aureus was sensitive to ANH-Lips when liposomes were in the blood plasma. However, they had no antimicrobial effect on Staphylococcus aureus when they were in sterile distilled water. Hence it opined

Table 2: Molecular identification of halophilic bacteria isolated. that Vancomycin hydrochloride release from ANH-Lips in the plasma, however, they were stable in distilled water.

\section{Molecular Identification of Halophilic Isolates}

The results obtained from 16S rRNA sequencing indicated that Mh1 isolated strain was Kocuria palustris DSM11925and Mh2 isolated strain was Salicola salis B2 (Table 2).

\begin{tabular}{|c|c|c|c|}
\hline Isolated Code & Bacterial Strains & Similarity & Accession Number \\
\hline Mh1 & Kocuria palustris DSM11925 & $99.90 \%$ & Y16263 \\
\hline Mh2 & Salicola salis B2 & $99.90 \%$ & DQ129689 \\
\hline
\end{tabular}

\section{Discussion}

Liposomes are the candidates in preparation of drug delivery systems. Recent studies showed the great potential of liposomes in cancer treatment [12]. The amphiphilic property of the phospholipid of liposomes leads to the formation of spherical particles. The space between phospholipid bilayer and liposomes surface cause various hydrophilic and hydrophobic drugs trapping [13]. Usually, liposomes are unstable and tend to accumulate and formation of mass, which greatly reduces their effectiveness. Therefore, structural modification of liposome increases their applications [14]. In the present study, we try to prepare liposome from halophilic lipids. Several studies illustrated that archaeal membrane lipids are composed of isoprenoid core (phytanyl) linked to either glycerol (Hanford and Peeples, 2002). Halophilic archaea are containing stronge membrane lipid against harsh conditions such as high-salt environments [15].

In the present study liposomes were prepared using halophilic organisms with the intention of achieving maximum information regarding liposomes and liposomes drug loading. As mentioned above Halophilic organisms are containing stronge membrane lipid, therefore, after isolation of halophilic organisms and extraction of their lipid, liposomes were prepared and the effect of $\mathrm{pH}$ and temperature on them were evaluated. The results indicated that the size of liposomes was changed in acidic and alkaline pH. Probably, this results obtained because of high concentration of $\mathrm{H}+$ ions in acidic $\mathrm{pH}$ and neutralization of negative charge of membrane phospholipids [16], which lead to joint liposomes to each other and become enlarge and contrary of this in alkaline $\mathrm{pH}$ and the size of liposomes reduced. Furthermore, our results indicated that the liposome size increased at high temperatures and decreased at low temperatures. To interpret, it must be noted that the fluidity of the membrane increasing follow by increasing temperature and reducing the zeta potential and hence the size of liposomes increased [17]. Yandrapati in 2012 [9] stated that the effect of pHs and temperatures on liposomes depended on the type of liposomes.

In addition, Yandrapati in 2012 after investigating on the stability of liposomes in plasma illustrated that plasma increase permeability of the liposome membrane, hence the rearrangement of membrane lipids and superficial absorption increased. Subsequently, the liposome size increased and loaded materials release from liposome (Yandrapati, 2012) [9]. According to our data liposomes of halophilic bacteria react to various conditions, which is due to the influence of the surface structure of these liposomes in different environments. Furthermore, novel halophilic bacteria isolates in our study (Kocuria palustris and Salicola salis) were able to grow in extreme conditions such as high concentration of salt. Therefore, we claim these bacteria are very good organisms for preparation of liposome and they are potentially drug delivery systems.

\section{Conflicts of Interest}

There are no conflicts of interest.

\section{References}

1. Olatunde O0, Benjakul S, Vongkamjan K, Amnuaikit T (2019) Influence of stabilising agents on the properties of liposomal encapsulated ethanolic coconut husk extract. International Journal of Food Science \& Technology 55(2): 702-711.

2. Barenholz Y, Berman T, Friedman D (2019) Inventors; Yissum Research Development Company of Hebrew University of Jerusalem, assignee. Stable liposomes for drug delivery. United States patent application US 16/440,189. 2019 Dec 12.

3. Makowski C, Lewis JD, Lepage C, Malla AK, Joober R, et al. (2019) Structural associations of cortical contrast and thickness in first episode psychosis. Cerebral Cortex 29(12): 5009-5021.

4. Huang Y, Anderson R (2002) Enhanced immune protection by a liposome-encapsulated recombinant respiratory syncytial virus (RSV) vaccine using immunogenic lipids from Deinococcus radiodurans. Vaccine 20(11-12): 1586-1592.

5. Paradiso FV, Nanni L, Merli L, De Marco EA, Catania VD, et al. (2016) Vacuum assisted closure for the treatment of complex wounds and enterocutaneous fistulas in full term and premature neonates: a case report. Italian journal of pediatrics 42(1): 2 .

6. Kozhikhova KV, Ivantsova MN, Tokareva MI, Shulepov ID, Tretiyakov AV et al. (2018) Preparation of chitosan-coated liposomes as a novel carrier system for the antiviral drug Triazavirin. Pharmaceutical development and technology 23(4): 334-342.

7. Hashemi T, Baseri SM, Bahador N (2014) Isolation of Halophilic Bacteria from Maharlu Salt Lake-Iran and their evaluation for the production of bioactive compounds. 
8. Corcelli A, Lobasso S (2006) 25 characterization of lipids of halophilic archaea. Methods in microbiology. 35: Elsevier pp. 585-613.

9. Yandrapati RK (2012) Effect of lipid composition on the physical properties of liposomes: a light scattering study.

10. Cazzola M, Mercuriali F, Brugnara C (1997) Use of recombinant human erythropoietin outside the setting of uremia. Blood, The Journal of the American Society of Hematology 89(12): 4248-4267.

11. Meure LA, Foster NR, Dehghani F (2008) Conventional and dense gas techniques for the production of liposomes: a review. Aaps Pharmscitech 9(3): 798.

12. Malam Y, Loizidou M, Seifalian AM (2009) Liposomes and nanoparticles: Nanosized vehicles for drug delivery in cancer. Trends Pharmacol Sci 30(11): 592-599.

13. Hua S, Wu SY (2013) The use of lipid-based nanocarriers for targeted pain therapies. Front Pharmacol 4: 143.

ISSN: 2574-1241

DOI: 10.26717/BJSTR.2020.29.004732

Majid Baserisalehi. Biomed J Sci \& Tech Res

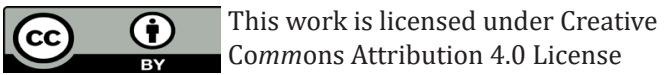

Submission Link: https://biomedres.us/submit-manuscript.php
14. Gupta M, Goyal AK, Paliwal SR, Paliwal R, Mishra N, et al. (2010) Development and characterization of effective topical liposomal system for localized treatment of cutaneous candidiasis. Journal of liposome research. 20(4): 341-350.

15. Jacquemet A, Barbeau J, Lemiegre L, Benvegnu T (2009) Archaeal tetraether bipolar lipids: Structures,functions and applications. Biochimie 91: 711-717.

16. Patel GB, Sprott GD (1999) Archaeobacterial ether lipid liposomes (archaeosomes) as novel vaccine and drug delivery systems. Crit Rev Biotechnol 19: 317-357.

17..Omolo CA, Megrab NA, Kalhapure RS, Agrawal N, Jadhav M, et al. (2019) Liposomes with $\mathrm{pH}$ responsive 'on and off'switches for targeted and intracellular delivery of antibiotics. Journal of liposome research p. 1-19.

$\begin{array}{ll}\text { BIOMEDICAL } & \text { Assets of Publishing with us } \\ \text { RESEARCHES } & \text { - Global archiving of articles } \\ \text { - Immediate, unrestricted online access }\end{array}$

